\title{
QUALIDADE DE MILHO VERDE ORGÂNICO E CONVENCIONAL EM ATMOSFERA MODIFICADA
}

Neli Cristina Belmiro dos Santos ${ }^{1}$, Silvia Antoniali ${ }^{2}$, Juliana Sanches ${ }^{3}$, Fabiano Tomehei Amikura $^{2}$, Silmara Cristina da Silva Doreto ${ }^{2}$

${ }^{1}$ APTA - Pólo Extremo Oeste, CP-67, CEP: 16.900-000, Andradina (SP).

${ }^{2}$ APTA - Pólo Extremo Oeste, Avenida Alcides F. Chagas, 122, CEP: 16.055-565, Araçatuba (SP).

${ }^{3}$ APTA - IAC, Centro de Engenharia e Automação, CP-26, CEP: 13.201-970 Jundiaí (SP).

RESUMO: O presente trabalho teve por objetivo verificar a qualidade pós-colheita de cultivares de milho para colheita de espigas verdes provenientes de cultivo orgânico e convencional embaladas em bandejas de poliestireno expandido recoberto com filme de policloreto de vinila (PVC) em condições ambientais. Foram utilizadas espigas de milho provenientes de cultivos orgânico e convencional conduzidos na área experimental sediada no município de Andradina-SP. Seis bandejas por cultivar foram acondicionadas a 25,5 \pm 2 ${ }^{\circ} \mathrm{C}$ e $60 \pm 8 \%$ UR por até 7 dias. As avaliações foram realizadas no início do experimento, 3 e 7 dias de armazenamento. O delineamento experimental utilizado foi o inteiramente casualizado, com três repetições, sendo os tratamentos dispostos em esquema fatorial 7 x 2 (cultivares: AG 1051, AG 4051, XB 7116, Cativerde, 20A55, BM 3061 e 2B587 e cultivo: orgânico e convencional). As unidades experimentais foram constituídas por cinco espigas em cada bandeja. Pelos resultados apresentados é possível concluir que a qualidade póscolheita de espigas de milho verde das cultivares testadas não é influenciada pelo sistema de cultivo (convencional e orgânico).

Palavras-chave: Zea mays. Qualidade. Conservação. Embalagem.

\section{QUALITY OF ORGANIC AND CONVENTIONAL GREEN CORN MODIFIED ATMOSPHERE}

\begin{abstract}
This study aimed to verify the quality of post-harvest maize cultivars for harvesting green ears from organic and conventional cultivation packed in polystyrene trays covered with polyvinylchloride film under ambient conditions. Been used corn cobs from organic and conventional crops conducted in the experimental area based in the city of Andradina-SP. Six trays of each cultivar were placed at $25,5 \pm 2{ }^{\circ} \mathrm{C}$ and $60 \pm 8 \% \mathrm{RH}$ for 7 days. Evaluations were performed at baseline, 3 and 7 days of storage. The experimental design was completely randomized with three replications and treatments arranged in a $7 \mathrm{x}$ 2 factorial (cultivar: AG 1051, AG 4051, XB 7116, Cativerde, 20A55, BM 3061 and 2B587 and farming: organic and conventional). The experimental units consisted of five spikes in each bin. The results presented one can conclude that the postharvest quality of green ears of corn cultivars is not influenced by cropping system (conventional and organic).
\end{abstract}

Key words: Zea mays. Quality. Conservation. Package.

Cultura Agronômica, Ilha Solteira, v.24, n.1, p.71-82, 2015 


\section{INTRODUÇÃO}

O milho (Zea mays L.) é amplamente cultivado e consumido em todos os continentes. Os Estados Unidos, a China e o Brasil são os maiores produtores mundiais (OLIVEIRA et al., 2009). A produtividade brasileira tem crescido sistematicamente, passando de $1.665 \mathrm{~kg}$ ha $^{-1}$ em 1980, para $3.600 \mathrm{~kg} \mathrm{ha}^{-1}$ em 2009 (CONAB, 2010). A comercialização de espiga de milho verde, em supermercados ou feiras livres, normalmente é feita em bandejas de poliestireno expandido, onde se acondiciona de quatro a cinco espigas despalhadas, envoltas por um filme de policloreto de vinila (PVC) transparente ou simplesmente acondicionadas em saco plástico transparente. A embalagem influi no processo metabólico das espigas, no que se refere à entrada de oxigênio, importante para a respiração aeróbica do produto, permitindo, assim, trocas gasosas. Estudos com embalagens de filme PVC esticável e filme plástico PD-941 mostram menores teores de amido quando em condições de refrigeração e, conseqüentemente, melhor conservação do produto para comercialização (MARCOS et al., 1999). Quando comercializado a granel, o milho suporta, no máximo, dois dias sem perder a qualidade e as características exigidas pelo mercado consumidor (FERNANDES; OLIVEIRA, 1985).

A disponibilidade de cultivares destinadas à produção de milho verde é pequena, havendo a necessidade de se desenvolverem novos híbridos apropriados para esse segmento.

Apesar do cultivo do milho ser bastante difundido nas principais regiões brasileiras, são poucas as informações sobre o comportamento de cultivares e características de espigas de milho verde sob cultivo orgânico (ARAÚJO et al., 2000; CARVALHO et al., 2003).

Segundo Souza (2011), o mercado mundial de alimentos orgânicos avança a uma taxa de crescimento anual entre 10 e 30\%. No Brasil, a venda interna dos produtos orgânicos em 2010 foi de R\$ 350 milhões, valor este superior em $40 \%$ ao registrado em 2009. As hortaliças, alimento orgânico mais procurado pelos brasileiros, representam a maior fatia deste mercado.

O presente trabalho teve por objetivo verificar a qualidade pós-colheita de cultivares de milho para colheita de espigas verdes provenientes de cultivo orgânico e convencional.

\section{MATERIAL E MÉTODOS}

Foram utilizadas espigas de milho provenientes de cultivos orgânico e convencional conduzidos na área experimental da APTA / Pólo Regional de Desenvolvimento Tecnológico dos Agronegócios do Extremo Oeste, sediado no município de Andradina-SP, localizado na região noroeste do Estado de São Paulo a $379 \mathrm{~m}$ de altitude, 2055'S e $51^{\circ} 23^{\prime} \mathrm{W}$, em 2010 e 2011, conforme recomendações técnicas para os dois sistemas de cultivos.

O delineamento experimental utilizado foi o inteiramente casualizado, com três repetições (bandejas), sendo os tratamentos dispostos em esquema fatorial $7 \times 2$, correspondente a sete cultivares (AG 1051, AG 4051, XB 7116, Cativerde 02, 20A55, BM 
3061 e 2B587) e dois sistemas de cultivo (orgânico e convencional). As unidades experimentais foram constituídas por cinco espigas em cada bandeja.

A colheita foi realizada manualmente, nas primeiras horas da manhã, à medida que cada cultivar atingia o estágio R3 (grão leitoso). Logo após a colheita as espigas foram transferidas, com palha, para o laboratório em Andradina-SP, onde foram descascadas manualmente e selecionadas quanto a cor, descartando-se as muitos verdes ou além do ponto de maturação desejado. As espigas foram embaladas em bandejas de poliestireno expandido recobertos com película de PVC, e imediatamente transportadas para o Laboratório Vegetal da Unidade de Pesquisa e Desenvolvimento de Araçatuba-SP onde foram pesadas em balança semi-analítica para obtenção do peso inicial das bandejas.

Seis bandejas por cultivar foram armazenadas em temperatura ambiente $\left(25,5 \pm 2{ }^{\circ} \mathrm{C} \mathrm{e}\right.$ $60 \pm 8 \%$ UR) por 7 dias. As avaliações foram realizadas no início do experimento e após 3 e 7 dias de armazenamento em temperatura ambiente. Os parâmetros avaliados foram: a) perda de massa: determinada através da pesagem em balança semi-analítica e os resultados expressos em porcentagem de perda de massa fresca, calculados por meio da seguinte fórmula: $\mathrm{PPF}=100-(\mathrm{PF} \times 100 / \mathrm{PI})$, em que $\mathrm{PPF}=$ perda de peso fresco $(\%) ; \mathrm{PF}=$ peso da matéria fresca final $(\mathrm{g})$; PI = peso de matéria fresca inicial $(\mathrm{g})$; b) Presença de odor fermentado, através de escala de notas: 1 = ausência de odor fermentado; 2 = levemente odor fermentado; 3 = moderadamente odor fermentado; 4 = forte odor fermentado; 5 = extremamente forte odor fermentado; c) qualidade visual, através de escala de murchamento segundo Braz et al. (2006) e; d) Incidência de podridão - porcentagem de espigas na bandeja com incidência de podridões.

Para a avaliação das propriedades químicas, as amostras dos grãos de milho verde foram retirados das espigas com auxílio de facas e homogeneizados em processador de alimentos Pratic blender Cadence BLD 300 e avaliados quanto ao: a) teor de sólidos solúveis, determinado em refratômetro digital (Reichert, modelo $\mathrm{r}^{2}$ mini) sendo os valores expressos em \%, b) carboidrato solúvel total, segundo a metodologia descrita por Dubois et al. (1956) e os resultados expressos em $\mathrm{g} 100 \mathrm{~g}^{-1}$, c) carboidrato redutor, determinado através da extração com os reagentes de cobre e fosfo-molíbdico e leitura em espectrofotômetro (BEL, modelo SP 1102), segundo Villela et al. (1973), e os resultados expressos g $100 \mathrm{~g}^{-1} \mathrm{e}$; d) teor de amido determinado segundo Dubois et al. (1956) e os resultados expressos em $\mathrm{g} 100 \mathrm{~g}^{-1}$. Os dados obtidos foram analisados através da análise de variância com teste F, aplicando-se o teste de Tukey (5\%) para comparar as médias dos tratamentos.

\section{RESULTADOS E DISCUSSÃO}

Para os tratamentos mantidos em temperatura ambiente, observa-se através da Tabela 1, que a variável carboidrato solúvel total apresentou significância $(\mathrm{P}<0,05)$ para a fonte de variação interação cultivar e sistema de cultivo nas diferentes épocas de armazenamento. Espigas produzidas em sistema convencional apresentaram valor médio de carboidrato solúvel total superior às produzidas em sistema orgânico, com maior evidência no híbrido

Cultura Agronômica, Ilha Solteira, v.24, n.1, p.71-82, 2015 
XB 7116. Esses valores corroboram àqueles observados por Kokuszka (2005) quando avaliaram os carboidratos entre variedades de milho produzidas em sistema agroecológico e convencional. Em seus estudos, a fotossíntese, que é o fator responsável pela formação de carboidratos no grão, também ocorreu em maior intensidade nos grãos em sistema de cultivo convencional. Segundo Caniato et al. (2007) o conteúdo de carboidrato solúvel total representa os açúcares estruturais presentes nos grãos, assim como o carboidrato redutor, responsável pelo sabor adocicado, característico do produto fresco. Os carboidratos são os constituintes bioquímicos mais abundantes nos vegetais, chegando a representar 50 a $80 \%$ do peso seco total destes. Eles são importantes fontes de energia e compõem a parte estrutural das células (KAYS, 1991). De modo geral, todas as cultivares apresentaram redução neste parâmetro no decorrer do armazenamento. Sendo o milho verde uma hortaliça de fruto que é colhido ainda imaturo, possui uma taxa respiratória muito elevada (CHITARRA; CHITARRA, 2005), o que indica que a diminuição dos carboidratos no período de armazenamento está relacionada com a utilização destes componentes como substrato do processo respiratório. Esta diminuição também foi observada por Rodriguez et al. (1991) quando estudou as mudanças nos carboidratos durante o desenvolvimento do grão e após a colheita da cultivar de milho doce 'Asukar'.

Tabela 1. Carboidrato solúvel total $\left(\mathrm{g} 100 \mathrm{~g}^{-1}\right)$ em espigas de milho verde cultivadas sob sistema convencional e orgânico e armazenadas a $25,5 \pm 2{ }^{\circ} \mathrm{C}$ e $60 \pm 8 \%$ UR por 7 dias.

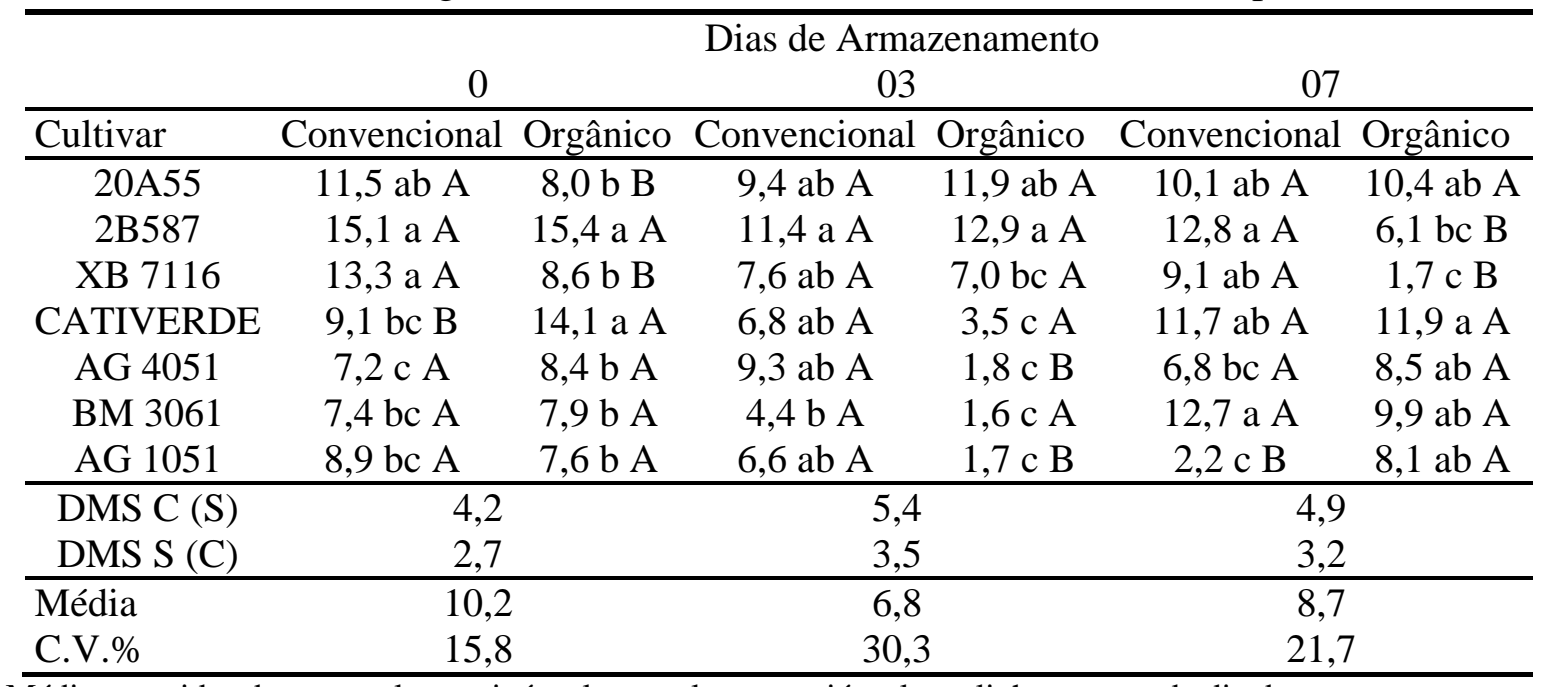

Médias seguidas de mesma letra minúscula na coluna e maiúscula na linha, para cada dia de armazenamento, não diferem entre si, pelo teste de Tukey $(\mathrm{P}<0,05)$.

No milho normal, os açúcares redutores estão presentes em maior quantidade nos primeiros estádios de amadurecimento (CREECH, 1968). Assim sendo, a composição em amido, polissacarídeos solúveis em água, açúcares redutores e sacarose no milho está intimamente relacionada com seu estádio de maturação (TSAI et al.,1970). Convém destacar que a deposição de amido aumenta com a evolução da maturação. No milho verde, como em outros vegetais frescos, carboidratos simples como sacarose e frutose e o teor de amido definem atributos de qualidade, devendo ser investigados nesse estágio para melhor recomendação ao produtor e aceitação do consumidor. 
Tabela 2. Carboidrato redutor $\left(\mathrm{g} 100 \mathrm{~g}^{-1}\right)$ em espigas de milho verde cultivadas sob sistema convencional e orgânico e armazenadas a $25,5 \pm 2{ }^{\circ} \mathrm{C}$ e $60 \pm 8 \%$ UR por 7 dias.

\begin{tabular}{|c|c|c|c|c|}
\hline & \multicolumn{3}{|c|}{ Dias de Armazenamento } & \\
\hline & 0 & 03 & 07 & \\
\hline \multicolumn{5}{|l|}{ Cultivar (C) } \\
\hline & & & Convencional & Orgânico \\
\hline $20 \mathrm{~A} 55$ & $3,7 \mathrm{~b}$ & $2,2 \mathrm{ab}$ & 4,0 ab A & 0,8 b B \\
\hline 2B587 & $7,1 \mathrm{a}$ & $4,9 \mathrm{a}$ & 4,6 a $\mathrm{A}$ & 4,6 a $\mathrm{A}$ \\
\hline XB 7116 & $5,5 \mathrm{ab}$ & $3,6 \mathrm{ab}$ & 0,2 с A & $0,8 \mathrm{~b} \mathrm{~A}$ \\
\hline CATIVERDE & $1,3 \mathrm{c}$ & $3,1 \mathrm{ab}$ & $1,1 \mathrm{c} \mathrm{A}$ & $2,2 \mathrm{ab} \mathrm{A}$ \\
\hline AG 4051 & $5,3 \mathrm{ab}$ & $1,9 \mathrm{~b}$ & 1,9 abc $A$ & $1,5 \mathrm{~b} \mathrm{~A}$ \\
\hline BM 3061 & $4,6 \mathrm{~b}$ & $2,2 \mathrm{ab}$ & 1,7 bc $\mathrm{A}$ & $0,3 \mathrm{~b} \mathrm{~A}$ \\
\hline AG 1051 & $5,1 \mathrm{~b}$ & $2,6 \mathrm{ab}$ & $1,4 \mathrm{bc} \mathrm{A}$ & $2,2 \mathrm{ab} \mathrm{A}$ \\
\hline \multicolumn{5}{|c|}{ Sistema de Cultivo (S) } \\
\hline Convencional & $4,8 \mathrm{a}$ & $3,8 \mathrm{a}$ & - & \\
\hline Orgânico & $4,5 \mathrm{a}$ & $2,0 \mathrm{~b}$ & - & \\
\hline Média & 4,7 & 2,9 & 1,9 & \\
\hline C.V.\% & 22,9 & 52,7 & 55,2 & \\
\hline \multicolumn{5}{|l|}{ Interação } \\
\hline $\mathrm{C} \times \mathrm{S}$ & NS & NS & $*$ & \\
\hline$\overline{D M S ~ C ~(S) ~}$ & - & - & 2,8 & \\
\hline DMS S (C) & - & - & 1,8 & \\
\hline
\end{tabular}

Médias seguidas de mesma letra minúscula na coluna e maiúscula na linha, para cada dia de armazenamento, não diferem entre si, pelo teste de Tukey $(\mathrm{P}<0,05)$.

Tabela 3. Teor de amido ( $100 \mathrm{~g}^{-1}$ ) em espigas de milho verde cultivadas sob sistema convencional e orgânico e armazenadas a $25,5 \pm 2{ }^{\circ} \mathrm{C}$ e $60 \pm 8 \%$ UR) por 7 dias.

\begin{tabular}{|c|c|c|c|c|}
\hline & \multicolumn{3}{|c|}{ Dias de Armazenamento } & \\
\hline & 0 & 03 & 07 & \\
\hline \multicolumn{5}{|l|}{ Cultivar (C) } \\
\hline & & & Convencional & Orgânico \\
\hline $20 \mathrm{~A} 55$ & $3,3 \mathrm{~b}$ & $1,9 \mathrm{ab}$ & $3,6 \mathrm{ab} \mathrm{A}$ & $0,7 \mathrm{~b}$ B \\
\hline 2B587 & $6,4 \mathrm{a}$ & $4,4 \mathrm{a}$ & 4,2 a $\mathrm{A}$ & 4,1 a $\mathrm{A}$ \\
\hline XB 7116 & $4,9 \mathrm{ab}$ & $3,2 \mathrm{ab}$ & 0,2 с A & $0,7 \mathrm{~b} \mathrm{~A}$ \\
\hline CATIVERDE & $1,2 \mathrm{c}$ & $2,8 \mathrm{ab}$ & $1,0 \mathrm{c} \mathrm{A}$ & $2,0 \mathrm{ab} \mathrm{A}$ \\
\hline AG 4051 & $4,8 \mathrm{ab}$ & $1,7 \mathrm{~b}$ & $1,7 \mathrm{abc} A$ & $1,4 \mathrm{~b} \mathrm{~A}$ \\
\hline BM 3061 & $4,2 \mathrm{~b}$ & $2,0 \mathrm{ab}$ & 1,6 bc A & $0,3 \mathrm{~b} A$ \\
\hline AG 1051 & $4,6 \mathrm{~b}$ & $2,4 \mathrm{ab}$ & $1,2 \mathrm{bc} A$ & $2,0 \mathrm{ab} \mathrm{A}$ \\
\hline \multicolumn{5}{|c|}{ Sistema de Cultivo (S) } \\
\hline Convencional & $4,3 \mathrm{a}$ & $3,4 \mathrm{a}$ & \multicolumn{2}{|l|}{-} \\
\hline Orgânico & $4,1 \mathrm{a}$ & $1,8 \mathrm{~b}$ & \multicolumn{2}{|l|}{-} \\
\hline Média & 4,2 & 2,6 & \multicolumn{2}{|l|}{1,8} \\
\hline C.V.\% & 22,9 & 52,7 & \multicolumn{2}{|c|}{55,2} \\
\hline \multicolumn{5}{|l|}{ Interação } \\
\hline $\mathrm{C} \times \mathrm{S}$ & NS & NS & \multicolumn{2}{|l|}{$*$} \\
\hline DMS C (S) & - & - & \multicolumn{2}{|l|}{2,5} \\
\hline DMS S (C) & - & - & \multicolumn{2}{|l|}{1,6} \\
\hline
\end{tabular}

Médias seguidas de mesma letra minúscula na coluna e maiúscula na linha, para cada dia de armazenamento, não diferem entre si, pelo teste de Tukey $(\mathrm{P}<0,05)$.

Cultura Agronômica, Ilha Solteira, v.24, n.1, p.71-82, 2015 
Na Tabela 2 e Tabela 3 estão apresentados os resultados referentes ao carboidrato redutor e amido, respectivamente. Observa-se que para estes parâmetros, assim como para o carboidrato solúvel total, ocorreu decréscimo dos valores com o decorrer do período de armazenamento. Para ambos os parâmetros verifica-se a significância para a fonte de variação interação cultivar e sistema de cultivo aos sete dias de armazenamento, sendo o híbrido 20A55 o que se apresentou estatisticamente diferente entre os sistemas de cultivo. Para Rodriguez et al. (1991) ao comparar os resultados com os da literatura, observaram que os níveis e alterações nos carboidratos de milho pode variar de híbrido para híbrido e que assim como o carboidrato solúvel total, o carboidrato redutor apresenta tendência de decréscimo durante o armazenamento. Entre os cultivares, nota-se que o híbrido $2 \mathrm{~B} 587$ foi o que se manteve com os maiores valores de carboidrato redutor e amido durante o período de armazenamento.

De maneira geral, observa-se que espigas de milho verde produzidas sob sistema de cultivo convencional apresentaram maiores valores de carboidratos redutores e amido que as cultivados organicamente.

Tabela 4. Sólidos solúveis (\%) em espigas de milho verde cultivadas sob sistema convencional e orgânico e armazenadas a $25,5 \pm 2{ }^{\circ} \mathrm{C}$ e $60 \pm 8 \%$ UR por 7 dias.

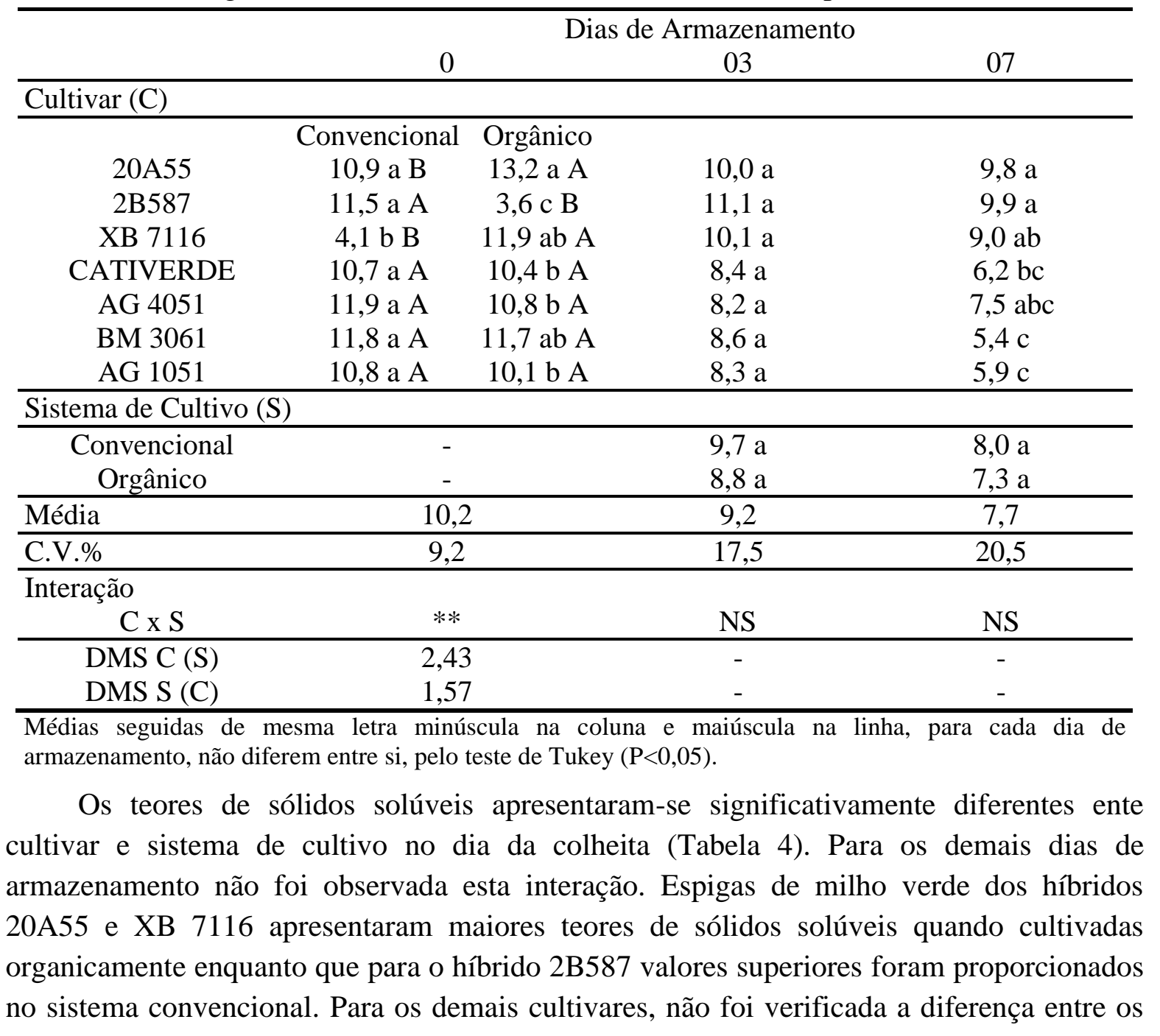

Cultura Agronômica, Ilha Solteira, v.24, n.1, p.71-82, 2015 
dois sistemas de cultivo, sendo que o híbrido XB 7116 apresentou a menor porcentagem $(4,1 \%)$ para o sistema convencional e o híbrido 2 B587 $(3,6 \%)$ para o sistema orgânico. Ao longo do período de armazenamento foi observada uma redução nos sólidos solúveis (média de 10,2 para 7,7), e o híbrido BM 3061 foi o que apresentou a maior queda deste parâmetro durante o período de estocagem (11,8 inicial para 5,4 aos 7 dias de estocagem). $\mathrm{O}$ mesmo comportamento também foi verificado por Mamede et al. (2009) e Zhu et al. (1992) ao armazenaram espigas de milho verde.

Durante a síntese de amido, em milho verde, ocorre a formação de polissacarídeos solúveis em água (MYERS et al., 2000) que são medidos como sólidos solúveis, e, por isso, são bem maiores que os de açúcares. Hale et al. (2005) e Zhu et al. (1992) encontraram correlações negativas para milho doce entre os valores de sólidos solúveis e açúcares totais.

Tabela 5. Presença de odor fermentado em espigas de milho verde cultivadas sob sistema convencional e orgânico e armazenadas a $25,5 \pm 2{ }^{\circ} \mathrm{C}$ e $60 \pm 8 \%$ UR por 7 dias. Notas de 1 a 5 , sendo 1 - ausência de odor fermentado e 5 - odor fermentado extremamente forte.

\begin{tabular}{|c|c|c|c|}
\hline \multirow{3}{*}{ Cultivar (C) } & \multicolumn{3}{|c|}{ Dias de Armazenamento } \\
\hline & \multicolumn{2}{|c|}{03} & \multirow[t]{2}{*}{07} \\
\hline & & & \\
\hline+2 & Convencional & Orgânico & \\
\hline $20 \mathrm{~A} 55$ & $2,3 \mathrm{ab} \mathrm{B}$ & 4,0 a $\mathrm{A}$ & $3,8 \mathrm{a}$ \\
\hline 2B587 & $2,7 \mathrm{ab} A$ & 2,3 a A & $4,5 \mathrm{a}$ \\
\hline XB 7116 & $2,0 \mathrm{~b} \mathrm{~A}$ & 2,3 a A & $4,5 \mathrm{a}$ \\
\hline CATIVERDE & $3,0 \mathrm{ab} \mathrm{A}$ & 3,7 a $\mathrm{A}$ & $4,7 \mathrm{a}$ \\
\hline AG 4051 & 4,0 a $\mathrm{A}$ & 2,3 a B & $4,7 \mathrm{a}$ \\
\hline BM 3061 & $2,7 \mathrm{ab} A$ & 2,3 a A & $4,5 \mathrm{a}$ \\
\hline AG 1051 & $2,3 \mathrm{ab} A$ & 2,3 a A & $4,3 \mathrm{a}$ \\
\hline \multicolumn{4}{|c|}{ Sistema de Cultivo (S) } \\
\hline Convencional & \multicolumn{2}{|c|}{-} & $4,3 \mathrm{a}$ \\
\hline Orgânico & \multicolumn{2}{|c|}{-} & $4,5 \mathrm{a}$ \\
\hline Média & \multicolumn{2}{|c|}{2,7} & 4,4 \\
\hline C.V.\% & \multicolumn{2}{|c|}{26,4} & 13,5 \\
\hline \multicolumn{4}{|l|}{ Interação } \\
\hline $\mathrm{C} \times \mathrm{S}$ & \multicolumn{2}{|c|}{$*$} & NS \\
\hline DMS C (S) & \multicolumn{2}{|c|}{1,9} & - \\
\hline DMS S (C) & \multicolumn{2}{|c|}{1,2} & - \\
\hline
\end{tabular}

Médias seguidas de mesma letra minúscula na coluna e maiúscula na linha, para cada dia de armazenamento, não diferem entre si, pelo teste de Tukey $(\mathrm{P}<0,05)$.

Na Tabela 5, observa-se que até o terceiro dia de armazenamento, as espigas de milho verde apresentavam-se, de modo geral, odor fermentado de leve a moderado. Ainda nesta tabela, pode-se verificar a interação significativa entre cultivares e sistemas de cultivo aos três dias de armazenamento. Vale ressaltar que o híbrido 20A55 cultivado organicamente e o híbrido AG 4051 cultivado sob sistema convencional apresentaram presença forte de odor fermentado já ao terceiro dia de armazenamento. Aos sete dias de armazenamento não foi detectada a diferença estatística entre as cultivares quanto à presença de odor fermentado, todavia todas se mostraram com odor forte a extremamente forte indicando perda de qualidade comercial das espigas. $\mathrm{O}$ acondicionamento das espigas de milho verde em

Cultura Agronômica, Ilha Solteira, v.24, n.1, p.71-82, 2015 
bandejas de poliestireno expandido recobertas com película de PVC deve ser visto com reservas quando não for refrigerado, pois, assim como Braz et al. (2006), verificou-se que as espigas embaladas desta maneira e mantidas em temperatura ambiente por três dias de armazenamento já apresentavam-se com odor fermentado.

Tabela 6. Incidência de podridão (\%) em espigas de milho verde cultivadas sob sistema convencional e orgânico e armazenadas a $25,5 \pm 2{ }^{\circ} \mathrm{C}$ e $60 \pm 8 \%$ UR por 7 dias.

\begin{tabular}{|c|c|c|c|c|}
\hline & \multicolumn{4}{|c|}{ Dias de Armazenamento } \\
\hline & \multicolumn{2}{|c|}{03} & \multicolumn{2}{|c|}{07} \\
\hline \multicolumn{5}{|l|}{ Cultivar (C) } \\
\hline & Convencional & Orgânico & Convencional & Orgânico \\
\hline 20A55 & $53,3 \mathrm{ab} \mathrm{A}$ & 73,3 a $\mathrm{A}$ & 33,3 b B & 88,9 a $\mathrm{A}$ \\
\hline 2B587 & $46,7 \mathrm{ab} A$ & $33,3 \mathrm{~b} \mathrm{~A}$ & 93,3 a $A$ & 73,3 a $A$ \\
\hline XB 7116 & $33,3 \mathrm{ab} A$ & $46,7 \mathrm{ab} A$ & 80,0 a $\mathrm{A}$ & 83,3 a $A$ \\
\hline CATIVERDE & $40,0 \mathrm{ab} A$ & $20,0 \mathrm{~b} A$ & 100,0 a $\mathrm{A}$ & 93,3 a $A$ \\
\hline AG 4051 & 60,0 a $\mathrm{A}$ & 13,3 b B & 77,8 a A & 100,0 a $\mathrm{A}$ \\
\hline BM 3061 & $20,0 \mathrm{~b}$ A & 26,7 b A & $73,3 \mathrm{ab} A$ & 80,0 a $\mathrm{A}$ \\
\hline AG 1051 & $46,7 \mathrm{ab} \mathrm{A}$ & $26,7 \mathrm{~b} \mathrm{~A}$ & 100,0 a A & 100,0 a $\mathrm{A}$ \\
\hline DMS C (S) & \multicolumn{2}{|c|}{40,0} & \multicolumn{2}{|c|}{42,0} \\
\hline DMS S (C) & \multicolumn{2}{|c|}{25,8} & \multicolumn{2}{|c|}{27,2} \\
\hline Média & \multicolumn{2}{|c|}{38,6} & \multicolumn{2}{|c|}{19,3} \\
\hline C.V.\% & \multicolumn{2}{|c|}{40,0} & \multicolumn{2}{|c|}{84,0} \\
\hline
\end{tabular}

Médias seguidas de mesma letra minúscula na coluna e maiúscula na linha, para cada dia de armazenamento, não diferem entre si, pelo teste de Tukey $(\mathrm{P}<0,05)$.

O mesmo comportamento foi observado para médias de incidência de podridão (Tabela 6), mas neste caso a interação entre cultivares e sistema de cultivo foi significativa para as duas épocas de análise (03 e 07 dias). Nota-se que os dois híbridos com forte presença de odor fermentado foram os que também apresentaram maior incidência de podridão (20A55 e AG 4051) já no terceiro dia de armazenamento. Não se observou uma relação entre o sistema de cultivo e a incidência de podridão visto que para algumas cultivares, as médias são maiores no sistema convencional e para outras no sistema orgânico.

Um fator de fundamental importância para a comercialização de produto destinado à alimentação humana é a aparência. Como não se tem um modo objetivo de determinar a qualidade visual de espigas de milho verde, optou-se em usar como meio de comparação a escala de murchamento proposta por Braz et al. (2006). Nela os autores apresentam uma escala subjetiva de 05 notas composta por fotos onde cada nota representa uma porcentagem de perda de peso, sendo $1-0 \%$ e $5-75 \%$ perda de peso. Esta mesma escala pode ser utilizada como critério de descarte, pois as espigas com qualidade visual referente à nota 03 (com aproximadamente $14 \%$ de perda de peso fresco das espigas) já não possuem mais valor comercial.

Através da Tabela 7 verifica-se que as espigas cultivadas convencionalmente encontravam-se, segundo a escala proposta, dentro dos padrões aceitáveis para comercialização aos três dias de armazenamento a $25,5 \pm 2{ }^{\circ} \mathrm{C}$ e $60 \pm 8 \%$ UR com exceção da variedade CATIVERDE. Devido à interação significativa, o mesmo não foi observado para 
as espigas cultivadas organicamente que apresentaram variações quanto à qualidade visual, sendo as cultivares 2B587, XB 7116 e BM 3061 as que se mantiveram mais adequadas para o consumo. Quando se analisou este parâmetro no sétimo dia de armazenamento, com exceção do híbrido XB 7116 orgânico, verificou-se que as espigas apresentaram-se com aspecto murcho, grãos enrugados e fora dos padrões de comercialização.

Tabela 7. Qualidade visual em espigas de milho verde cultivadas sob sistema convencional e orgânico e armazenadas a $25,5 \pm 2{ }^{\circ} \mathrm{C}$ e $60 \pm 8 \%$ UR por 7 dias. Notas de 1 a 5 , baseadas na escala de murchamento proposta por Braz et al. (2006).

\begin{tabular}{|c|c|c|c|c|}
\hline \multirow{3}{*}{$\begin{array}{l}\text { Cultivar (C) } \\
\end{array}$} & \multicolumn{4}{|c|}{ Dias de Armazenamento } \\
\hline & \multicolumn{2}{|c|}{03} & \multicolumn{2}{|c|}{07} \\
\hline & & & & \\
\hline & Convencional & Orgânico & Convencional & Orgânico \\
\hline 20A55 & $1,0 \mathrm{~b} \mathrm{~B}$ & 3,0 a A & 1,7 a A & $3,0 \mathrm{ab} \mathrm{A}$ \\
\hline 2B587 & $1,3 \mathrm{~b} \mathrm{~A}$ & $1,0 \mathrm{c} \mathrm{A}$ & 2,3 a A & $2,7 \mathrm{ab} A$ \\
\hline XB 7116 & $1,0 \mathrm{~b} \mathrm{~B}$ & $1,3 \mathrm{bc} \mathrm{A}$ & 2,7 a $\mathrm{A}$ & $1,0 \mathrm{~b} \mathrm{~B}$ \\
\hline CATIVERDE & 2,7 a $A$ & 2,7 a $A$ & 3,0 a B & 4,7 a $A$ \\
\hline AG 4051 & $2,0 \mathrm{ab} \mathrm{A}$ & 2,7 a A & 1,7 a B & 3,7 a $A$ \\
\hline BM 3061 & $2,0 \mathrm{ab} \mathrm{A}$ & 1,0 c B & 1,7 a B & 3,3 a A \\
\hline AG 1051 & $1,7 \mathrm{ab} \mathrm{A}$ & $2,3 \mathrm{ab} A$ & $1,7 \mathrm{a} \mathrm{B}$ & 4,0 a A \\
\hline DMS C (S) & \multicolumn{2}{|c|}{1,2} & \multicolumn{2}{|c|}{2,1} \\
\hline DMS S (C) & \multicolumn{2}{|c|}{0,7} & \multicolumn{2}{|c|}{1,4} \\
\hline Média & \multicolumn{2}{|c|}{1,8} & \multicolumn{2}{|c|}{2,6} \\
\hline C.V.\% & \multicolumn{2}{|c|}{22,3} & \multicolumn{2}{|c|}{30,9} \\
\hline
\end{tabular}

Médias seguidas de mesma letra, minúscula na coluna e maiúscula na linha, para cada dia de armazenamento, não diferem entre si, pelo teste de Tukey $(\mathrm{P}<0,05)$.

Tabela 8. Perda de massa (\%) em espigas de milho verde cultivadas sob sistema convencional e orgânico e armazenadas a $25,5 \pm 2{ }^{\circ} \mathrm{C}$ e $60 \pm 8 \%$ UR por 7 dias.

\begin{tabular}{ccc}
\hline & Dias de Armazenamento & \\
& 03 & 07 \\
\hline Cultivar (C) & $3,5 \mathrm{a}$ & $5,6 \mathrm{a}$ \\
\hline $20 A 55$ & $3,2 \mathrm{abc}$ & $5,8 \mathrm{a}$ \\
$2 \mathrm{~B} 587$ & $2,7 \mathrm{abc}$ & $5,6 \mathrm{a}$ \\
XB 7116 & $3,4 \mathrm{ab}$ & $6,9 \mathrm{a}$ \\
CATIVERDE & $2,7 \mathrm{bc}$ & $5,9 \mathrm{a}$ \\
AG 4051 & $2,6 \mathrm{c}$ & $5,7 \mathrm{a}$ \\
BM 3061 & $2,7 \mathrm{bc}$ & $6,1 \mathrm{a}$ \\
AG 1051 & & \\
\hline Sistema de Cultivo (S) & $2,9 \mathrm{a}$ & $5,4 \mathrm{~b}$ \\
\hline Convencional & $3,0 \mathrm{a}$ & $6,5 \mathrm{a}$ \\
Orgânico & 3,0 & 5,9 \\
\hline Média & 13,9 & 15,2 \\
\hline C.V.\% & & $\mathrm{NS}$ \\
\hline Interação & $\mathrm{NS}$ & \\
C x S & & \\
\hline
\end{tabular}

Médias seguidas de mesma letra na coluna, não diferem entre si, pelo teste de Tukey $(\mathrm{P}<0,05)$.

Cultura Agronômica, Ilha Solteira, v.24, n.1, p.71-82, 2015 
Observa-se, na Tabela 8, aumento da perda de massa (em média, $3 \%$ no $3^{\circ}$ dia de armazenamento para 5,9\% no $7^{\circ}$ dia de armazenamento) ao longo do armazenamento para os todos os híbridos de milho verde independentemente do sistema de cultivo. Segundo Chitarra e Chitarra (2005), o principal fator responsável pela perda de massa durante o armazenamento de frutas e hortaliças é a transpiração. Perdas na ordem de 3\% a $6 \%$ são suficientes para causar marcante declínio na qualidade. Já Kays (1991) citado por Braz et al. (2006) considera 7\% como perda de massa máxima admitida para o milho doce.

A utilização da atmosfera modificada passiva proporcionou a retenção da matéria fresca nas espigas de milho verde armazenadas a $25,5 \pm 2{ }^{\circ} \mathrm{C}$ e $60 \pm 8 \% \mathrm{UR}$, pois como o considerado por Kays (1991), todas as cultivares estudadas obtiveram perdas de massa inferiores a proposta como máxima admitida, corroborando com os resultados apresentados por Henz et al. (1996) quando avaliaram a utilização de filmes plásticos na conservação de milho verde, porém suficientes para apresentarem aspecto de murchamento (Tabela 8), com exceção do híbrido XB 7116.

\section{CONCLUSÕES}

A qualidade pós-colheita de espigas de milho verde provenientes de cultivo orgânico e convencional, das cultivares testadas, não foi influenciada pelo sistema de cultivo.

A temperatura ambiente favoreceu a perda dos teores de carboidratos e amido durante o armazenamento.

A utilização da bandeja de poliestireno expandido recoberto com filme PVC em condições ambientais proporcionou a presença de odor fermentado aos 3 dias de armazenamento.

A cultivar 20A55 cultivada organicamente foi a mais suscetível à incidência de podridão.

\section{AGRADECIMENTO}

À FAPESP pela concessão do apoio financeiro.

\section{REFERÊNCIAS BIBLIOGRÁFICAS}

ARAÚJO P. C.; PERIN A.; MACHADO A. T.; ALMEIDA D. L. Avaliação de diferentes variedades de milho para o estádio de "verde" em sistemas orgânicos de produção. In: CONGRESSO NACIONAL DE MILHO E SORGO, 23, Uberlândia, 2000. Resumos...: Uberlândia: ABMS/Embrapa Milho e Sorgo/Universidade Federal de Uberlândia, 2000. (CD ROM).

BRAZ R. F.; GAlVÃO, J. C. C.; FINGER, F. L.; MIRANDA, G. V.; PUIATTI, M.; ALMEIDA, A. A. Perda de peso pós-colheita de espigas de milho-verde em função de 
diferentes formas de acondicionamento. Revista Brasileira de Milho e Sorgo, Sete Lagoas, v.5, n. 1, p.139-144, 2006.

CANIATO, F. F.; GALVÃO, J. C. C.; FINGER, F. L.; PUIATTI, M.; OLIVEIRAS, D. A.; FERREIRA, J. L. Quantificação de açúcares solúveis totais, acúcares redutores e amido nos grãos verdes de cultivares de milho na colheita. Ciência e Agrotecnologia, Lavras, v. 31, n. 6, p.1893-1896. 2007.

CARVAlHO, G. J.; TEIXEIRA, C. M.; MARQUES, E. L. S.; ALMEIDA, K.; FONTANÉTTI, A. Produção orgânica de milho-verde em consórcio com feijão-de-porco (Canavalia ensiformes). Horticultura Brasileira, Brasília, v. 21, n. 2, p. 275, 2003. Suplemento 1.

CHITARRA, M. I. F.; CHITARRA, A. D. Pós-colheita de frutas e hortaliças: fisiologia e manuseio. 2 ed. Lavras: FAEPE, 2005. 785 p.

CONAB - COMPANHIA NACIONAL DO ABASTECIMENTO. Comparativo de área, produção e produtividade. Série histórica. Disponível em: <http://www.conab.gov.br/conabweb/index.php?PAG=131>. Acesso em: 20 out. 2010.

CREECH, R. G. Carbohydrate synthesis in maize. In: NORMAN, A. G. Advances in Agronomy. New York: Academic, 1968. p. 275-289

DUBOIS, M.; GUILlES, K. A.; HAMILTON, J. K., REBERS, P. A.; SMITH, F. Colorimetric method for determination of sugar and related substances. Analytical Chemistry, Washington, v. 2, n. 3, p.350-356, 1956.

FERNANDES, J. C.; OLIVEIRA, L. A. A. Aspectos do mercado atacadista do milho verde na Ceasa-RJ. Niterói: PESAGRO-RIO, 1985. 4 p. (Comunicado técnico, 147).

HALE, T. A.; HASSELL, R. L.; PHILLIPS, T. Refractometer measurements of soluble solid concentration do not reliably predict sugar content in sweet corn. HortTechnology, Alexandria, v. 15, n. 3, p.668-672, 2005.

HENZ, G. P.; NOJOSA, G. B. A.; MENDONÇA, N. D. Conservação pós-colheita de espigas de milho verde cv. AG 519. Horticultura Brasileira, Brasília, v. 14, p.89, 1996. Suplemento.

KAYS, E. J. Postharvest physiology of perishable plant products. New York: Van Nostrand Reinhold, 1991. 532 p.

KOKUSZKA, R. Avaliação do teor nutricional de feijão e milho cultivados em sistemas de produção convencional e agroecológico na região Centro-Sul do Paraná. 2005. 113 f.

Cultura Agronômica, Ilha Solteira, v.24, n.1, p.71-82, 2015 
Dissertação (Mestrado em Agronomia - Fitotecnia e Fitossanitarismo) - Universidade Federal do Paraná, Curitiba, 2005.

MAMEDE, A. M. G. N.; CHITARRA, A. B.; FONSECA, M. J. O.; SOARES, A. G.; FERREIRA, J. C. S.; LIMA, L. C. O. Conservação pós-colheita de espigas de milho verde minimamente processado sob diferentes temperaturas. Ciência e Agrotecnologia, Lavras, v. 33, n. 1, p.200-206, 2009.

MARCOS, S. K.; HONÓRIO, S. L.; JORGE, J. T.; AVELAR, J. A. A. Influência do resfriamento do ambiente de armazenamento e da embalagem sobre o comportamento póscolheita do milho-verde. Revista Brasileira de Engenharia Agrícola e Ambiental, Campina Grande, v. 3, n. 1, p.41-44, 1999.

MYERS, A. M.; MORELL, M.K.; JAMES, M.G.; BALL, S.G. Recent progress toward understanding biosynthesis of the amylopectin crystal. Plant Physiology, Waterbury, v. 122, n. 4, p.989-997, 2000.

OLIVEIRA, F. A.; CAVALCANTE, L. F.; SILVA, I. F.; PEREIRA, W. E.; OLIVEIRA, J. C.; FILHO, J. F. C. Crescimento do milho adubado com nitrogênio e fósforo em um Latossolo Amarelo. Revista Brasileira de Ciências Agrárias, Recife, v. 4, n. 3, p.238-244, 2009.

RODRIGUEZ, F. M.; LUBAG, A. J. M.; REVILLEZA, J. M. J. R.; MENDOZA, L. B. M.; SALAZAR, A. M. Changes in carbohydrates during kernel development and after harvest of a philippine supersweet corn cultivar. Philippine Journal of Crop Science, Laguna, v. 26, n. 1, p.19-23, 1991.

SOUZA, J. L. Hortaliças orgânicas: agregando valor, saúde e saldos ambientais. Horticultura Brasileira, Brasília, v. 29, n. 2, artigo da capa, 2011.

TSAI, C. Y.; SALAMINI, F.; NELSON, O. E. Enzymes of carbohydrate metabolism in developing endosperm of maize. Plant Physiology, Bethesda, v. 46, n. 2, p.299-336, 1970.

VILLELA, G., BACILA, M. TASTALDI, H. Técnicas e experimentos de bioquímica. Rio de Janeiro: Guanabara - Koogam, 1973. 552 p.

ZHU, S.; MOUNT, J. R.; COLLINS, J. L. Sugar and soluble solids changes in refrigerated sweet corn (Zea mays L). Journal of Food Science, Chicago, v. 57, n. 2, p.454-457, 1992.

Cultura Agronômica, Ilha Solteira, v.24, n.1, p.71-82, 2015 